\title{
Research on Wildlife Protection Technology in the Construction Period of Xinjiang Desert Gobi Expressway
}

\author{
Zhaoming Wang ${ }^{1,2 *}$ Gang Zhou ${ }^{3}$, Shegang Shao ${ }^{1,2}$, Xiaomin $\mathrm{Wu}^{4}$, Yufeng Zhu ${ }^{5}$, Hongfeng Zhang ${ }^{4}$, \\ ${ }^{1}$ Research Institute of Highway, Ministry of Transport, Beijing, 100088, China. \\ ${ }^{2}$ Key Laboratory of Environmental Protection Technology on Road Traffic, Ministry of Transport, Beijing, 101102, Beijing. \\ ${ }^{3}$ Xinjiang Uygur Autonomous Region Traffic Construction Administration, Urumqi, Xinjiang Province, 830002, China. \\ ${ }^{4}$ Shaanxi Institute of Zoology, Xian, Shannxi Province, 710032, China. \\ ${ }^{5}$ Zhonglu Hi-tech Transportation Technology Group co. LTD, Beijing, 100088, China.
}

\begin{abstract}
In this paper, the author is taking the protection of wildlife for the purpose for researching. The authors are taking the protection of animals and plants specific measures to research in the construction management. Taking the protection of wild animals and plants along the highway in the Xinjiang desert Gobi area as a research object, conservation research was carried out, and protection suggestions and measures were put forward.
\end{abstract}

\section{Construction management}

(1) Strengthen the education of ecological protection for construction personnel. The construction personnel shall be educated on the environment and wildlife protection awareness, and publicize the wildlife protection regulations. The construction personnel shall be given promotional pictures to protect the wildlife resources. The construction personnel are strictly prohibited from destroying the rare animal resources. If wild animals are found during construction, report and protect them in time, and strictly hunt wild animals.

(2) Prohibit illegal hunting, trapping and poisoning of wild animals, and effectively control other activities that threaten the reproduction and reproduction of wild animals.

(3) If wild animals are found during construction, construction should be suspended.

(4) Environmental protection publicity boards shall be set up at the construction site to prohibit construction workers from destroying vegetation outside the project area and hunting wild animals.

\section{Protect vegetation}

(1) In order to effectively protect vegetation, strictly control the occupation of land in the project design, minimize the occupation of forest land with medium and high coverage, and compensate for the loss of land resources in accordance with relevant regulations.

(2) Strictly regulate the scope of construction activities. Vehicles and machinery should be driven on planned roads. It is forbidden to drive at will, crush vegetation, strictly control the range of disturbance to the ecological environment, and effectively protect the turf within the construction area. It is repaved to the slope of the railway subgrade.

(3) The construction access road shall be arranged within the range of permanent land to reduce the floor area of the new construction access road.

(4) Take measures such as fences and ribbon protection to limit the occupation and disturbance scope of the project, do a good job of construction organization, and use the existing site as much as possible.

(5) Project waste, construction and domestic garbage should be piled up in a fixed location and cleared and transported in a timely manner. The location and method of disposal must be approved by the local environmental protection department. Drainage of waste water and waste residue during the construction period is strictly prohibited, and domestic sewage shall be discharged into the sewage collection tank. During the construction process, pollutants such as oil and chemicals are strictly prohibited from entering the water body, and chemicals containing harmful substances should not be stacked near the water body to effectively protect the current status of water environmental functions.

(6) Implement soil and water conservation measures. The spoil yard, material yard, construction area, and construction access road shall adopt effective soil and water loss prevention and control measures. After the project is over, land levelling and vegetation restoration shall be carried out on the temporary land occupation, temporary roads, borrow pits and spoil grounds in a timely manner, so that the construction is completed, the materials are exhausted and the site is cleared.

(7) Warning signs should be set up in the project area to strengthen environmental protection publicity and education for construction personnel, and it is strictly forbidden to destroy vegetation and hunt wild animals. 
(8) Reasonably use and develop desert forest and pasture resources, implement protection in accordance with the "Forest Law" and "Grassland Law", prohibit unauthorized logging, unauthorized reclamation, and other activities to maintain the environmental functions of the desert ecosystem.

\section{Protect animals}

(1) During subgrade construction, first slow down the slope to facilitate wildlife crossing the road from the subgrade.

(2) Reasonably arrange the construction operation time, reduce the operation content during wild animal breeding, migration, and wintering, and slow down the impact on animal activities.

(3) In view of the special requirements of animals for noise, vibration and light, construction should be carried out during the day as much as possible, and with little or no construction at night;

(4) Construction camps, precast yards, mixing stations and other places with a lot of personnel activities should avoid wild animal habitats;

(5) In road sections where wild animals frequently infest, roadblocks should be set up during roadbed construction to prevent wild animals from being injured or injured;

(6) For large spoil grounds, facilities such as retaining walls and drainage shall be designed, and shall be completely isolated from the habitats of wild animals;

(7) After the construction is completed, the waste materials and sheds on the temporary land shall be thoroughly cleaned.

(8) The facilities that can be used in wildlife protection facilities or can be reused shall be properly handled and protected.

\section{Controlling construction noise}

(1) Noise reduction measures, such as noise reduction or sound insulation measures, shall be taken during the road construction operation to reduce noise generation;

(2) Construction vehicles should strengthen daily maintenance to reduce noise and oil pollution from mechanical equipment;

(3) Construction transportation vehicles should use closed transportation as much as possible to remind drivers to prohibit whistle and exercise at low speeds on sections where wild animals are frequented;

(4) Reasonably arrange the construction time of each process and the operation time of high-noise equipment, try to avoid vibration compaction and drilling processes overlapping with the breeding period of surrounding wild animals, and avoid drilling around the animal habitat without any noise reduction measures, Piling or underwater cutting operations.

(5) Use construction methods and equipment with small impact during construction to reduce the use of high-noise and high-intensity vibration equipment.

\section{Controlling air pollution}

(1) Prefabricated yards, mixing stations, stockyards and other places that generate a lot of atmospheric dust shall be set in open areas in the downwind direction of sensitive areas of wildlife, with a distance of at least $300 \mathrm{~m}$.

(2) It is strictly forbidden to occupy wetland and keep it away from wild animal habitats as much as possible; dustproof measures such as sealing or shielding and moisturizing shall be adopted in the stockyard.

(3) Sprinkling water and dust-reducing measures shall be taken on working surfaces and construction processes prone to wind and dust.

(4) For some highly polluting wastes, such as toxic liquid, phosphorous slag, slag, fly ash, etc., closed transportation should be adopted, and the site should be cleaned as soon as possible.

(5) Take hardening, water spraying and dust reduction measures at the construction site to avoid dustprone construction operations in windy weather.

\section{Controlling sewage}

(1) Construction wastewater such as prefabrication yards and mixing stations should be reused after precipitation or sprinkled to reduce dust, and not directly discharged.

(2) The domestic sewage in the construction camp shall be treated with dry toilets or septic tanks, and shall be cleaned and transported regularly.

\section{Solid waste control}

(1) Domestic garbage should be collected by classification and concentrated, and cleaned up, cleared or disposed on-site in time.

(2) The construction waste is collected and recycled after centralized collection, and cannot be used for disposal at the designated spoil ground.

(3) During the construction of the project, no littering and harmful substances shall be allowed to harm wild animals.

(6) Use transportation vehicles and non-road mobile machinery that meet pollutant discharge standards to standardize the construction material transportation routes, and cover measures for material transportation.

(7) Asphalt concrete mixing equipment with good sealing performance, high dust removal efficiency and low pollution discharge is used for material mixing.

(8) When the excavated bare site is not under construction, it should be covered with dust screens and sprinkled regularly to reduce dust pollution.

\section{Acknowledgments}

NSFC (Natural Science Foundation of China, 4161183, "Study on the impact of road network on habitat safety of large wildlife in xinjiang's typical desert and gobi region". Xinjiang construction and communications bureau science and technology project"Research and 
demonstration of key technologies for wildlife passage construction in desert and gobi region".

\section{References}

1. Van der Geer, J., Hanraads, J.A.J., Lupton, R.A. (2010) The art of writing a scientific article. J. Sci. Commun., 163: 51-59.

2. Brodie, J.F., Paxton, M., Nagulendran, K., Balamurugan, G., Clements, G.R., Reynolds, G., Jain, A., Hon, J., 2016. Connecting science, policy, and implementation for landscape-scale habitat connectivity. Conserv. Biol. 30, 950-961.

3. Elliot, N.B., Cushman, S.A., Macdonald, D.W., Loveridge, A.J., 2014. The devil is in the dispersers: predictions of landscape connectivity change with demography. J. Appl. Ecol. 51, 1169-1178.

4. Forman, R.T.T., Alexander, L.E., 1998. Roads and their major ecological effects. Annu. Rev. Ecol. Syst. 29, 207-231.

5. KAZA TFCA Secretariat, 2014. Kavango-Zambezi Transfrontier Conservation Area: Master Integrated Development Plan, 2014-2019. KAZA TFCA Secretariat, Kasane, Botswana.

6. Kiffner, C., Albertini, M., Ede, A., Donnellan, B., Hahn, N., McGinnis, M.A., Nietlisbach, N.A., Tate, J., Kioko, J., 2015. Performance of individual species as indicators for large mammal species richness in Northern Tanzania. Ecol. Indic. 53, 7077.

7. Naidoo, R., Du Preez, P., Stuart-Hill, G., Beytell, P., Taylor, R., 2014. Long-range migrations and dispersals of African buffalo (Syncerus caffer) in the Kavango-Zambezi Transfrontier Conservation area. Afr. J. Ecol. 52, 581-584.

8. Naidoo, R., Chase, M.J., Beytell, P., Du Preez, P., Landen, K., Stuart-Hill, G., Taylor, R., 2016. A newly discovered wildlife migration in Namibia and Botswana is the longest in Africa. Oryx 50, 138-146. 